\title{
MANAGEMENT OF THE INFANT DURING AND AFTER CARDIAC SURGERY
}

\author{
W. A. Donos, M.D.
}

CONGENITAL CARDIAC ANOMAaliEs, if untreated, carry a high mortality in infancy and early childhood. If the malformation is severe, medical therapy is often found inadequate and the patient succumbs to his defect at an early age. Recent improvements in diagnostic and operative techniques have made early interference feasible. If an accurate diagnosis can be established, surgical correction or palliation is possible in some cases.

Infants with severe cardiac malformations who have responded poorly or not at all to medical therapy are now subjected to extensive investigational procedures including right and left heart catheterization for pressure and saturation estimations, dye dilution curves, and venous and arterial angiograms using biplane cineradiography. These diagnostic procedures and the definitive surgical procedures may be carried out on an elective or on an emergency basis.

The small size and poor physical condition of these infants presents a real challenge in management during and after surgery. The purpose of this presentation is to present our experience in handling patients of this type who have come to surgery in our Hospital during the past six years. We have limited our discussion to patients ùnder one year of age, the youngest being three days, with a variation in weight from 6 to 20 pounds. These figures do not represent our total experience in handling the small infant with cardiac disability. Many cardiac patients over one year of age weigh less than 20 pounds, as underdevelopment is one of the manifestations of their disability. The cardiac patient who has reached one year of age does not fall into the category where medical therapy has failed. Many of these children may be carried on a strict medical regime for one to two years before accurate diagnosis is established or surgery becomes necessary. These patients often improve with age and surgery may be postponed until they reach a more suitable size.

Our experience has increased gradually from 1957 to 1962, as shown in Table I. The total number of cases reviewed are 76 , with 20 deaths occurring in the immediate postoperative period. There were no operating room deaths, Our series includes all surgical procedures on the heart and great vessels within the thorax, including those cases operated on for double aortic arch or anomalous vascular ring.

A mortality figure of 26 per cent may not be considered high when one is aware that these infants could not be improved or maintained symptom-free on intensive medical therapy. Indeed, if cardiac function was not improved during surgery the patient was unlikely to survive thoracotomy.

-Department of Anaesthesia, Vancouver General Hospital, Vancouver, Britsh Columbia, Assistant Professor, Department of Surgery, University of British Columbia.

Can. Anaes. Soc. J., vol. 10, no. 6, November, 1963 
As mentioned previously, consideration was given to corrective or palliative surgical procedures. Initial procedures in 1957 and 1958 were for the most part either extracardiac corrections or shunts. In 1959, in addition to these palliative procedures, corrective surgery was attempted on three patients with ventricular septal defect and all died in the recovery room. These poor results were considered to be due to the pump oxygenator and failure to adapt the perfusion

TABLE I

Total Cases and Number of Postoperativi: Deaths PER Year IN INFANTS UNDER 1 Year L'NDERGOING Cardiac Surgeri

\begin{tabular}{ccc}
\hline Year & Number of cases & Number of deaths \\
\hline 1957 & 6 & 0 \\
1958 & 7 & 2 \\
1959 & 1 & 4 \\
1960 & 12 & 5 \\
1961 & 23 & 4 \\
1962 & 21 & 5 \\
Total & 76 & 20 \\
\hline
\end{tabular}

equipment to the circulating volumes and haemodynamics of the infant. For this reason an intensive programme was initiated in the Laboratory to improve extracorporeal circulation for the small infant. Our study resulted in the development of a modified disk-type oxygenator, 9 inches in length, all fittings and tubing scaled to paediatric volumes. $A$ disk oxygenator was selected to avoid the possibility of minute bubbles or anti-foam which may be deposited in the arterial circulation using a bubble oxygenator. The small arterial tree of the infant makes these deposits hazardous as compared with the adult patient. Particular attention was paid to inflow and outflow cannulations, pre- and post-perfusion blood volume estimations, and monitoring of arterial and venous pressures and blood chemistry. ${ }^{1}$ Experience in the Laboratory resulted in improved operating room techniques in both open and closed cardiac procedures. Our over-all experience, as shown in Table II, indicates a preponderance of palliative over corrective surgical procedures, due in part to the nature of the defects such as tricuspid atresia and transposition of the great vessels, and in part to the recent development of the infant perfusion equipment. Banding of the pulmonary artery to improve pulmonary function in the presence of a ventricular septal defect has been satisfactory. As a result of improvement in by-pass techniques corrective surgery for ventricular septal defects and auricular septal defects, with or without anomalous pulmonary venous drainage, has been successful. ${ }^{2}$

Except for the special considerations involved in the use of the pump oxygenator, infants undergoing either palliative or corrective cardiac surgery are handled in the same fashion. Patients under $10-15$ pounds receive no premedication. Above this weight they receive hyoscine gr. 1/600 with meperidine 2/3 mg./lb. of body weight one hour preoperatively. Patients under 10 pounds are intubated awake; over this weight, induction is with nitrous oxide and"fluothane

${ }^{\circ} \mathrm{G}$. F. Strong Laboratory, University of British Columbia. 
TABLE II

Types of Procedures per Year Indicating Result as Living or Dead*

\begin{tabular}{|c|c|c|c|c|c|c|c|c|c|c|c|c|}
\hline \multirow[b]{2}{*}{ Defect and procedure } & \multicolumn{2}{|c|}{1957} & \multicolumn{2}{|c|}{1958} & \multicolumn{2}{|c|}{1959} & \multicolumn{2}{|c|}{1960} & \multicolumn{2}{|c|}{1961} & \multicolumn{2}{|c|}{1962} \\
\hline & $\mathrm{L}$ & $\mathrm{D}$ & $\mathrm{L}$ & $\mathrm{D}$ & $\mathrm{L}$ & D & L & D & $\mathrm{L}$ & $\mathrm{D}$ & $\mathrm{L}$ & $\mathrm{D}$ \\
\hline Vascular ring & 4 & 0 & 1 & 0 & 1 & 0 & 1 & 0 & & & & \\
\hline $\begin{array}{l}\text { Patent ductus arteriosus } \\
\text { Tetralogy of fallot }\end{array}$ & 1 & 0 & 3 & 0 & & & 3 & 0 & 6 & 0 & 6 & 0 \\
\hline $\begin{array}{l}\text { Blalock } \\
\text { 1 etratogy or }\end{array}$ & 1 & 0 & & & & & 1 & 0 & 1 & 0 & & \\
\hline $\begin{array}{l}\text { Potts } \\
\text { Tricusnid }\end{array}$ & & & & & & & & & 1 & 1 & & \\
\hline Potts & & & & & 3 & 1 & 1 & 0 & & & & \\
\hline Glen & & & & & & & $\frac{1}{1}$ & $\begin{array}{l}0 \\
1\end{array}$ & & & & \\
\hline Transposition of great vessels & & & & & & & & & & & & \\
\hline Potts & & & 1 & 0 & & & & & & & & \\
\hline Baffes & & & & & & & 2 & 1 & 3 & 1 & 1 & 1 \\
\hline $\begin{array}{l}\text { Hanlon } \\
\text { A.S.D. }\end{array}$ & & & & & & & & & & & 4 & 1 \\
\hline A.D. Closed & & & & & & & & & 1 & 0 & & \\
\hline With a nomalous veins & & & & & & & & & 2 & 1 & 2 & 1 \\
\hline V.S.D. & & & & & & & & & & & & \\
\hline Closed & & & & & 3 & 3 & & & & & 2 & 0 \\
\hline Banding P.A. & & & & & & & 1 & 1 & 81 & 0 & 3 & 0 \\
\hline $\begin{array}{l}\text { Aortic stenosis } \\
\text { Multiple defects }\end{array}$ & & & 2 & 2 & & & 2 & 2 & 1 & 1 & $\begin{array}{l}2 \\
1\end{array}$ & $\frac{1}{1}$ \\
\hline
\end{tabular}

or oxygen and fluothane if the patient is cyanotic. Following induction and intubation an arterial cutdown is carried out on the radial artery in order to monitor direct arterial pressure continuously. A venous cutdown is performed on either the external jugular vein in the neck or on the saphenous vein at the ankle for intravenous infusions or medications. These cutdowns are also used to obtain arterial and venous samples for blood chemistry and oxygen saturation determinations. Blood chemistry estimations using the micro-Astrup method and oxygen saturations using a Waters cuvette are carried out $\mid$ routinely. ${ }^{{ }^{7}}$ Lead II of the electrocardiogram is also observed. Fluothane concentrations required during cutdown and positioning of the patient, approximately 2 per cent using a Fluotec vaporizer, have been noted to reduce arterial blood pressure to $50-60 \mathrm{~mm}$. $\mathrm{Hg}$, a direct effect of fluothane on the myocardium. Following the skin incision the concentration may be reduced to 0.5 to 1 per cent for maintenance of anaesthesia and the blood pressure usually rises to $90-100 \mathrm{~mm}$. $\mathrm{Hg}$. The constant monitoring of radial artery pressures has proved to be of great value in indicating excessive concentrations of the agent as well as the general cardiovascular status of the patient. Radial artery cutdown and cannulation at this age is technically difficult but possible. Anaesthesia is maintained without intravenous agents of any kind using controlled respiration and a Bloomquist Infant Circle.

During cardiac manipulation or anastomoses, which may jeopardize pulmonary circulation or cardiac output, electrocardiographic and radial artery monitoring is most important to observe impending cardiac failure, particularly in those procedures where the ventricles are not exposed. This failure is most often manifested 
by a marked bradycardia with falling blood pressure. Although these signs may occur as a result of low blood volume from inadequate replacement or from vagal stimulation, they are most often due to an atonic myocardium and may ${ }^{\prime}$ be reversed by the intravenous use of calcium chloride in a dosage of 1 to 2 c.c. of 10 per cent solution intravenously. Following surgery and during closing of the thoracotomy, anaesthetic concentrations are reduced and by the end of the procedure the patient is wide awake, and crying.

If surgical correction or improvement has been obtained there is a rapid improvement in cardiac function and the postoperative care consists of careful observation from the standpoint of respiratory function. The radial artery cannula may be left in place to monitor arterial pressure, but most particularly to follow arterial $\mathrm{pH}, p \mathrm{CO}_{2}$, and standard bicarbonate. By" this means the respiratory or metabolic components of the acid-base balance may be observed and treated. Respiratory acidosis is treated by maintaining a clear airway and oxygen therapy if necessary and metabolic acidosis lby administration of intravenous sodium bicarbonate. $^{3}$

Postoperative blood volume maintenance is important and recently we have undertaken to do pre- and post-operative blood volume estimations using radioiodinated human serum albumin and the volumetron computer. This information is considered, along with the estimations of blood loss obtained by weighing drapes and sponges in the operating room. Replacement is made by an assessment of weighed loss, volumetron resulls, arterial and venous pressure, haemoglobin, and consideration of the effect of the correction or production of vascular shunts on the circulating blood volume.

If surgery has not improved cardiac action, the postoperative condition of the patient gradually deteriorates despite therapy. This deterioration is usually indicated by a low arterial pressure, poor colour, listlessness, and most particularly by the development of a metabolic acidosis which responds only temporarily to bicarbonate therapy.

Tracheotomy for respiratory control with a Bird respirator or to facilitate suction has been used on two occasions late in the postoperative period. We have encountered serious difficulties in this age group with respirator failure, and blockage of the tracheostomy tube with" secretions. Tracheostomy tubes available for use in infants are usually too long and carinal irritation or endobronchial intubation may occur. Closing of the tracheostomy in infants is also a difficult if not hazardous procedure. At present tracheotomy is considered only if intensive respiratory therapy proves inadequate.

There is some indication that postoperative haemorrhagic atelectasis occurs when by-pass is prolonged. This may be due to surface tension changes in the alveoli. At the present time we are attempting to estimate these changes and to study the effect of hyperbaric oxygen in their treatment experimentally.

Death in our series has been due most commonly to unsuspected defects found at surgery not amenable to correction or improvement. These defects have included single ventricle with hypoplastic aorta, hypoplastic pulmonary artery, truncus arteriosus, and Ebsteins nalformation. The next most common cause of 
death has been due to postoperative respiratory obstruction due to a mucous plug or aspiration. Despite attentive postoperative supervision sudden respiratory embarrassment can occur.

One death occurred in a patient of 5 months with aortic stenosis who suddenly arrested while awaiting the induction of anaesthesia prior to surgery. He was quickly intubated and external cardiac massage was carried out while the chest was opened and by-pass prepared. Despite repair of the aortic stenosis and resuscitation of the heart-beat the patient subsequently died, no doubt as a result of the inadequacy of circulation for the period preceding by-pass. This case is particularly indicative of the poor-risk category of the patients considered for surgery.

\section{SUMmaRy}

Infant mortality due to cardiäc anomalies treated medically is high. Some of these patients respond well to corrective or palliative surgery following comprehensive diagnostic procedures. Management of these patients during and after surgery may be enhanced by monitoring the electrocardiogram, arterial and venous pressures, blood chemistry, and by blood volume studies. The use of an infant pump oxygenator has improved the handling of those infdnts who require cardiopulmonary by-pass.

Postoperative care is important. However, if surgical interference has not improved the cardiovascular haemodynamics, death will occur.

\section{RÉSUMÉ}

La mortalité infantile due à des anomalies cardiaques traitées médicalement est élevée. Un certain nombre de ces malades supportent bien la chirurgie correctrice ou palliative à la suite de mesures diagnostiques adéquates. L'on peut faciliter la surveillance de ces malades après la chirurgie, en visualisant l'électrocardiogramme, les pressions artérielle et veineuse, la chimie sanguine et en étudiant le volumé sanguin. L'usage d'une pompe oxygénatrice pour enfant a amélioré la manutension des enfants chez qui la circulation extracorporelle est indiquée.

Les soins postopératoires sont importants. Toutefois. si la chirurgie n'a pas amélioré l'hémodynamique, c'est la mort. La cause la plus fréquente de la mort dans notre série a été attribuable à des défauts' insoupçonnés, découverts au cours de la chirurgie mais non susceptibles de correction ou d'amélioration.

\section{REFERENCES}

1. Asmmore, P. G.; Pratt, R. F.; McGillivhay, R. A.; \& Fonseng, E. G. An Experimental Study of Cardiopulmonary By-pass in the Small Animal. Can. J. Surg. 5: 218 (1962).

2. Asmone, P. G. Management of Cardiopulmonary Bly-pass in the Infant. In press.

3. Dodos, W. A. \& Fonseng, E. G. Acid-Base Balance in Open Heart Surgical Patients Canad. Anaesth. Soc. J. 9: 488 (1962). 